\title{
O IMPÉRIO DA SUPREMACIA BRANCA \\ E A FRENTE NEGRA BRASILEIRA \\ AS REPRESENTAÇÕES SOBRE AS RELAÇÕES RACIAIS \\ DA AMÉRICA LATINA NO JORNAL AFRO-AMERICANO \\ CHICAGO DEFENDER (1916-1940)
}

Flavio Thales Ribeiro Francisco ${ }^{1}$

\section{A linha de cor e a ascensão do Chicago Defender nos Estados Unidos}

Na virada entre os séculos XIX e XX, a associação entre supremacia branca e identidade nacional ganhava força, consolidando as inúmeras práticas de segregação racial nos Estados Unidos. As lideranças negras que emergiram nesse momento, a partir da criação de organizações políticas, passaram a desafiar o repertório racista da sociedade norte-americana, reivindicando a igualdade de direitos. Nesse mesmo período, já havia intelectuais negros que trabalhavam com a perspectiva internacional, analisando o processo de colonização dos povos do continente africano e comparando-o ao processo de racialização dos negros da diáspora negra, sobretudo os da América do Norte. William Du Bois, o mais notável deles, conectando as experiências da diáspora e dos africanos, identificou um fenômeno amplo de racialização que se prolongaria ao longo do século XX. O avanço dos Estados Unidos sobre a América Central e o Pacífico 
reforçou a sensação entre as lideranças afro-americanas de que o país seria um dos centros de irradiação do racismo global. ${ }^{2}$

Na imprensa negra, para além do diagnóstico pessimista de expansão do racialismo, a perspectiva internacional também contemplava os espaços considerados livres da hierarquização racial. O jornal Chicago Defender, acompanhando a ampliação das redes do ativismo negro nas primeiras décadas do século XX, quando se consolidou como o periódico de maior influência da imprensa negra, incorporou à sua política editorial a divulgação das experiências negras da América Latina para o público afro-americano. Conforme o ativismo negro se mobilizava em torno de uma agenda integracionista, o jornal utilizava as relações entre negros e brancos do Brasil como referência positiva, demonstrando a possibilidade de construir uma ordem social sem tensões raciais. Assim, a sociedade brasileira foi recorrentemente explorada como exemplo de padrão pacífico de relações raciais, característica comum à maioria dos países latino-americanos.

O Chicago Defender começou a circular em 1905. Seu editor e idealizador, Robert Abbott, havia deixado o Sul do país e vislumbrou nas grandes cidades do Norte melhores oportunidades de trabalho. Com o diploma de Direito em mãos, contudo, encontrou portas fechadas, e a publicação de um jornal voltado para a população negra da cidade de Chicago apareceu como segunda opção. O periódico negro, que começou com estrutura e receita limitadas, demorou-se a conquistar leitores; entretanto, a partir de 1910, com uma cobertura sensacionalista sobre a violência que envolvia a população negra de Chicago, iniciou sua ascensão como o principal jornal da imprensa negra afro-americana. ${ }^{3}$

O Chicago Defender foi reconhecido por sua campanha a favor da migração dos negros do Sul para os grandes centros do Norte do país. Durante a Grande Migração (1915-1930), o jornal denunciou a violência racial nos estados sulistas, recomendando aos afro-americanos a migração

2 Para acompanhar o debate sobre racialização da ordem internacional no século XX, cf. Robert Vitalis, White World Order, Black Power Politics: The Birth of American International Relations, Ithaca: Cornell University Press, 2013.

3 Flavio Thales Ribeiro Francisco, $O$ novo negro na diáspora: modernidade afro-americana e as representações sobre o Brasil e a França no jornal Chicago Defender (1916-1940), São Paulo: Intermeios, 2016. 
para cidades como Nova Iorque, Chicago e Detroit. As primeiras décadas do século XX nos Estados Unidos foram marcadas por um deslocamento de pessoas que teria um grande impacto sobre as experiências políticas da população negra. A Grande Migração, fenômeno em que milhões de negros do Sul do país se dirigiram para os centros urbanos do Norte em busca de oportunidades de emprego, criou áreas com grandes concentrações negras. ${ }^{4} \mathrm{O}$ Sul do país era considerado, além de uma região com economia limitada, um espaço estruturado a partir de rigorosa hierarquia racial que inviabilizava o exercício da cidadania. ${ }^{5}$ Apesar das tensões entre negros e brancos estarem presentes também nas cidades do Norte, estas foram tratadas como espaços inclusivos que possibilitavam o acesso a ocupações nas indústrias.

Nesse contexto, as cidades do Norte, onde as práticas de repressão se manifestavam em escala menor, testemunharam a ascensão de inúmeras organizações políticas que energizaram o ativismo negro no país. Esse é o momento em que o movimento negro nos Estados Unidos inicia sua institucionalização, estabelecendo as bases para a transformação de uma diversidade de vozes ativistas em grupo de pressão no cenário político. Essa primeira geração, que se posicionou de maneira veemente contra a hierarquia racial na sociedade norte-americana, ficou conhecida pelo termo New Negro, que traduziria uma nova postura dos negros diante do racismo.

Como consequência desse movimento vibrante, o espaço de atuação das lideranças negras também se ampliou, transcendendo as fronteiras nacionais. A Primeira Guerra Mundial, com a participação de combatentes negros nos campos de batalha europeus, despertou o interesse dos afro-americanos nas experiências negras estrangeiras, dentre elas as de soldados africanos que lutavam entre as tropas dos impérios europeus. ${ }^{6}$ Desde o século XIX, eles já direcionavam seus olhares para

4 James Grossman, Land of Hope: Chicago, Black Southerners, and The Great Migration, Chicago: University of Chicago Press, 1989.

5 Vanessa Holloway, Black Rights in Reconstruction Era, New York: Hamilton Books, 2018; Eric Foner, Reconstruction: America's Unfinished Revolution, 1863-1877, New York: Harper \& Row, 1988.

6 Adriane Danette Lenthz-Smith, Freedom Struggles: African Americans and World War I, Cambridge: Harvard University Press, 2009. 
outras populações negras, principalmente no continente africano, em um momento em que se discutia acaloradamente a emigração de negros para a Libéria. Contudo, no século XX, os ativistas negros estavam mais interessados em acompanhar os processos de integração das populações negras em diferentes projetos de nação nas Américas, na África e na Europa, promovendo um debate sobre cidadania dos negros nos Estados Unidos.

O periódico afro-americano, que tinha uma abordagem integracionista, em meio à luta contra a segregação racial, identificou no Brasil e na França duas ordens sociais orientadas por valores que asseguravam uma fraternidade racial. Enquanto o Chicago Defender construiu em suas páginas um quadro nacional marcado por atentados à cidadania negra, em perspectiva internacional deu grande atenção aos exemplos de harmonia racial que julgou encontrar nos dois países.

Desde 1827, quando o Freedom's Journal passou a circular entre uma minoria de negros livres de Nova Iorque em um período de escravidão, os periódicos cumpriram o papel de expressar as vozes da população negra, revelando uma perspectiva singular no cenário político norte-americano. Essa imprensa nasce com a preocupação de problematizar o processo de marginalização e degradação dos negros não submetidos à escravidão, manifestando também suas posições abolicionistas e a rejeição aos projetos de emigração para o continente africano, considerado por muitos políticos e algumas lideranças negras como solução para os conflitos raciais no país. ${ }^{7}$

Após a abolição da escravidão e as falhas de projetos para incluir socialmente os libertos nos Estados Unidos, a imprensa negra encarou novos desafios na luta pelos direitos civis previstos na Constituição norte-americana. $\mathrm{O}$ aumento do público leitor dos periódicos afro-americanos, possibilitando tiragens semanais acima de cem mil exemplares, deu fôlego extra para os jornais do início do século XX, o que oportunizou a profissionalização das redações. A imprensa negra no período de ascensão do Chicago Defender consolidou a formação de uma esfera pública negra de dimensão nacional desenvolvida no século XIX - os negros do

7 Frankie Hutton, The Early Black Press in America, 1827 to 1860, Westport: Greenwood Publishing Group, 1992; Jane Rhodes, Mary Ann Shadd Cary: The Black Press and Protest in The Nineteenth Century, Bloomington: Indiana University Press, 1999. 
Sul do país se informavam sobre os acontecimentos em outras regiões, assim como o leitor da cidade de Chicago poderia acompanhar as experiências da população negra na cidade de Atlanta, no estado da Geórgia. Nesse sentido, as publicações negras se transformaram em instrumentos fundamentais para a articulação do ativismo negro nos Estados Unidos, e o Chicago Defender atuou ativamente no cenário político que se configurava naquele momento.

Aproveitando a euforia dos migrantes negros em torno das oportunidades supostamente oferecidas nos grandes centros do Norte, o Chicago Defender explorou sistematicamente os exemplos de violência no Sul do país, difundindo a representação da região como o espaço de opressão da população afro-americana. Em contraposição, as cidades do Norte foram retratadas no periódico de Robert Abbott como espaços livres de práticas racistas, nos quais os negros poderiam ascender socialmente. Enquanto supostamente os negros sulistas se encontravam em um ambiente degradado pelo legado da escravidão, no Norte do país surgia um novo negro, associado à modernidade norte-americana. O Chicago Defender apostou na formação de ordens sociais inclusivas nas grandes metrópoles do Norte, onde poderia se iniciar um processo de mobilidade social negra:

O Chicago Defender convida todos para vir ao Norte, onde há bastante espaço para os homens bons, sóbrios e trabalhadores. Aqui há bastante trabalho. Para aqueles que não irão trabalhar, as cadeias cuidarão de você. Quando você tiver os seus 90 dias de trabalho duro, você terá aprendido como trabalhar. Em qualquer lugar do país a vida é melhor do que no Sul [...]. Não deixe os malucos te enganarem, venha se juntar ao grupo dos livres. Deixe a opressão para trás. Quando você atravessar o Rio Ohio, respire o ar fresco e questione-se: "Por que eu não vim antes?".

As cidades do Norte dos Estados Unidos foram tratadas pelo Chicago Defender como espaços cosmopolitas que propiciariam a emergência de um novo negro alinhado à modernidade norte-americana. $\mathrm{O}$ velho negro representava o universo das relações raciais sulistas permeadas 
pelo legado da escravidão, uma estrutura social que se readequava para manter a população negra às margens. Na ótica do periódico, o dinamismo da economia dos grandes centros industriais se encarregaria de absorver os trabalhadores negros, reforçando o processo de modernização da população negra. Portanto, o Chicago Defender não fazia uma crítica à ordem capitalista, seu discurso revelava a intenção de incluir os afro-americanos ao capitalismo norte-americano. O novo negro era uma representação difundida pelo jornal que anunciava uma nova era de mudanças nas relações raciais, reforçando um processo de redenção negra após anos de escravidão.

O caráter assimilacionista da agenda do Chicago Defender se aproximou das posições políticas de lideranças negras de outros países nas Américas. Os ativistas negros de São Paulo e de Cuba nas primeiras décadas do século XX, por exemplo, consideraram esse período como um momento de transição no qual a população negra deixava a condição de escravidão para se integrar a uma ordem capitalista, elaborando narrativas de uma redenção negra. ${ }^{9}$ Essa redenção propagada pelos líderes negros cubanos e brasileiros não tinha como ponto de reflexão somente o lugar do negro na economia, havia também uma referência estética orientada por valores que deveriam conduzir a "elevação moral" dos negros. Esses grupos formavam uma "elite" negra assimilada que problematizava a presença de expressões culturais de origens africanas, consideradas como barreiras para o progresso dos negros nos dois países.

No entanto, o projeto integracionista do jornal, que tinha como elemento fundamental de seu repertório a ideia de metrópoles negras dos grandes centros do Norte, foi abalado por uma onda de violência que varreu todo o território norte-americano no verão sangrento de 1919. ${ }^{10}$ Ao contrário do que propagava o Chicago Defender, as tensões raciais

9 Kim Butler, Freedoms Given, Freedoms Won: Afro-Brazilian in Post-Abolition São Paulo and Salvador, New Brunswick: Rutgers University Press, 1998; Alejandro de la Fuente, $A$ Nation for All: Race, Inequality, and Politics in Twentieth Century Cuba, Chapel Hill: The University of Carolina Press, 2001; Frank Andre Guridy, Forging Diaspora: Afro-Cubans and African-Americans: in a World of Empire and Jim Crow, Chapel Hill: University of North Carolina Press, 2010.

10 Janet Abu-Lughod, Race, Space, and Riots in Chicago, New York, and Los Angeles, Nova York: Oxford University Press, 2007; William Tuttle, Race Riot: Chicago in the Summer of 1919, Champaign: University of Illinois Press, 1996. 
não estavam restritas às cidades do Sul; de uma forma ou de outra, as hierarquias raciais se constituíram em todas as regiões do país. A cidade de Chicago, maior referência de mobilidade social negra, se transformou em palco de um dos mais violentos enfrentamentos entre negros e brancos, revelando uma tensão que aumentava à medida que as comunidades negras se expandiam em consequência justamente da Grande Migração.

Robert Abbott, em seu periódico, reconheceu os limites da sociedade norte-americana, diminuindo o discurso eufórico em torno de uma mobilidade social negra. Contudo, a agenda integracionista que se configurou nas páginas do Chicago Defender não sofreu alterações, apenas mudou de orientação. Se a possibilidade de ascensão de um novo negro não era uma realidade nos Estados Unidos, o mesmo processo poderia acontecer em outros países. Esse é o momento em que o periódico passa a explorar sistematicamente as notícias e informações sobre o Brasil, difundindo representações de fraternidade racial na sociedade brasileira.

\section{Robert Abbott na América Latina}

Como parte dessa nova tendência editorial interessada nos brasileiros, Robert Abbott se organizou para uma jornada pela América Latina, em 1923, e outra pela Europa, em 1929. O jornalista tinha a clara intenção de testemunhar as relações entre negros e brancos, entrando em contato com um padrão de relações raciais distintas do norte-americano. $\mathrm{O}$ roteiro latino-americano de Abbott incluiu o Brasil, a Argentina, o Uruguai, o Chile, o Peru, Panamá e Cuba. Enquanto na América do Sul o afro-americano identificou uma modernidade latino-americana na qual as populações negras estavam incluídas, no Panamá e em Cuba, países localizados em uma zona sob a influência da política externa norte-americana, ele observou o que entendeu ser uma deterioração das relações raciais, influenciadas pelo racismo norte-americano.

Desde 1916, o Chicago Defender publicava notícias sobre o Brasil, utilizando principalmente o relato dos poucos afro-americanos que haviam circulado por cidades brasileiras. Um marco da cobertura do periódico foi a contratação da cantora soprano Patti Brown, que faria turnê pela América do Sul, para relatar suas experiências em Salvador 
e no Rio de Janeiro. A artista descreveu o intenso processo de miscigenação brasileira, definindo-o como fator elementar na formação de uma sociedade sem as tensões raciais dos norte-americanos. Brown pintou um cenário favorável para a população negra brasileira, demonstrando a presença de profissionais negros em diversas atividades da economia, o que supostamente não ocorria com os afro-americanos.

Eu visitei muitos prédios públicos e percebi que os negros predominavam nesses espaços. No correio, um edifício que havia sido construído por um empreiteiro negro, o encarregado tinha a pele morena. Além daqueles em treinamento, os atendentes e os carteiros eram mestiços. Nos bancos, nas casas de comércio, nas lojas e nas mecânicas, negros, brancos, homens e mulheres de aparência inteligente falam português e espanhol... Os policiais, os bombeiros, os condutores de bondes são de todas as cores. Os mais prósperos médicos, advogados, jornalistas e pensadores têm a pele escura. Eu tive um encontro com o Arcebispo do Amazonas que tem autoridade sobre brancos e negros em sua paróquia, ele era um homem negro. ${ }^{11}$

Em 1923, a ideia de um paraíso racial brasileiro já se consolidava entre os afro-americanos, pois desde o século XIX foi se constituindo a representação de uma escravidão branda no Brasil. Os abolicionistas negros reproduziram a retórica da harmonia racial brasileira para se contrapor à hierarquia racial nos Estados Unidos. Nesse sentido, Robert Abbott apenas ingressou em uma linhagem de afro-americanos que, desde a década de 1840, difundiu sistematicamente a representação de fraternidade racial brasileira por meio da imprensa negra. ${ }^{12}$

No caso específico de Robert Abbott, durante sua jornada, sua missão era a de informar de maneira detalhada seus leitores sobre as relações entre negros e brancos no Brasil e outros países da América Latina, retratando uma realidade distinta da dos norte-americanos. O jornalista,

11 "Country Where Brains Count”, Chicago Defender, 01/04/1916, p. 6.

12 Luciana da Cruz Brito, "Impressões norte-americanas sobre escravidão, abolição e relações raciais no Brasil escravista" (Tese de Doutorado, Programa de Pós-Graduação em História Social da Universidade de São Paulo, 2014), p. 91. 
em passagem pelas cidades do Rio de Janeiro e de São Paulo, relatou o processo de ascensão social dos cidadãos negros, que passaram a ocupar posições de prestígio, como médicos, advogados e engenheiros. Em sua perspectiva, os negros não encaravam a discriminação e a segregação racial, as barreiras enfrentadas pelos afro-americanos não estavam presentes na sociedade brasileira. Assim, a partir de uma minoria de negros ascendentes, Robert Abbott ignorou ou não entendeu as particularidades da hierarquia racial no Brasil e reforçou a ideia de uma fraternidade racial brasileira capaz de integrar de maneira efetiva sua população negra.

Quase toda raça existente parece estar presente na sociedade brasileira, existe um crescimento populacional constante através da imigração. Mas, a despeito da grande variedade e amplas diferenças físicas e mentais, existe um estado absoluto de harmonia social. Negros e brancos se casam sem provocar qualquer espécie de desaprovação. Mais: a tendência parece ser a de encorajar o casamento entre diferentes grupos, como brancos e africanos - o ideal é o de uma sociedade inteiramente homogênea em seu sangue. ${ }^{13}$

As dissonâncias entre os relatos dos afro-americanos e a realidade brasileira eram consequências das diferenças entre os padrões de relações raciais apresentados entre as regiões do Brasil e dos Estados Unidos. A regra do one-drop rule, que vigorava na sociedade norte-americana, por exemplo, ordenava a construção de categorias raciais completamente distintas das dinâmicas sociais brasileiras. ${ }^{14} \mathrm{O}$ presidente Nilo Peçanha, que apresentava pouquíssimos traços negros, foi apresentado aos leitores do Chicago Defender como o primeiro presidente negro do Brasil. ${ }^{15}$ Assim, muitos cidadãos considerados brancos na realidade brasileira eram enquadrados como negros no sistema de classificação dos Estados Unidos. A construção do branco brasileiro, que poderia ser concebida mesmo sem a "pureza racial", não foi incorporada aos relatos afro-americanos,

13 “My Trip Through South America”, Chicago Defender, 18/08/1923, p. 13.

$14 \mathrm{O}$ termo se refere à categorização racial que determina que um ascendente negro, mesmo distante por gerações, define a identidade racial negra de uma pessoa. Cf. Frank Sweet, The Legal History of Color Line: The Rise and The Triumph of The One-Drop Rule, Palm Coast: Backintyme, 2005.

15 “Brazil Ideal Country for BLACK Man”, Chicago Defender, 22/01/1916. 
possibilitando a apresentação de um quadro auspicioso nas narrativas do jornal Chicago Defender. Em um espaço transnacional, como apontam Julian Hooks e Brent Edwards, os intelectuais engajados na análise de outras sociedades muitas vezes apresentam dificuldades para traduzir dinâmicas raciais de outro contexto social. ${ }^{16}$

Os relatos sobre os outros países da América do Sul também revelaram dissonâncias, destacando uma cultura democrática sem manifestações de preconceito contra indígenas e negros. Assim como no caso do Brasil, o jornalista afro-americano, sem compreender as dinâmicas das relações sociais nos países visitados, deixou de mencionar histórias marcadas pela marginalização de minorias raciais. AArgentina, com sua população negra diminuta, se transformou em um país tolerante, capaz de integrar os poucos negros identificados nas ruas de Buenos Aires.

A escravidão nunca se configurou como uma instituição na Argentina, o número de negros sempre foi pequeno em qualquer época. Os tipos distintos de negros de tempos atrás, e que eram mais presentes, chegaram por meio da fronteira com o Brasil e foram todos absorvidos. Todos os negros que se encontram nas ruas têm origem brasileira ou vieram do Caribe e estão há pouco tempo no país. O índio da América do Sul, base étnica no continente nos dias de hoje, ainda que semelhante ao do índio norte-americano, é infinitamente superior. Ele criou uma forma de civilização, até então jovem, mas que foi brutalmente desenraizada. [...] Todas as atividades estão abertas, é muito comum ver policiais e bombeiros negros. De fato, eles ocupam várias funções, presentes em posições dignas no exército e na marinha. ${ }^{17}$

A cada passo de sua jornada pela América do Sul, Robert Abbott foi construindo uma modernidade sul-americana capitaneada por centros econômicos como Rio de Janeiro, São Paulo, Montevidéu e Buenos

16 Brent Hayes Edwards, The Practice of Diaspora: Literature, Translation, and The Rise of Black Internationalism, Cambridge: Harvard University Press, 2003; Juliet Hooker, Theorizing race in the Americas: Douglass, Sarmiento, Du Bois, and Vasconcelos, New York: Oxford University Press, 2017.

17 "My Trip Through South America", Chicago Defender, 22/09/1923, p. A1. 
Aires. Em seu relato constituiu-se uma narrativa de ascensão negra no pós-abolição, que retratou um processo bem-sucedido de integração e transformação dos negros brasileiros em cidadãos. Nesse sentido, o relato do jornalista afro-americano, publicado em forma de artigos no Chicago Defender, foi fundamental para difundir para um público mais amplo a representação de uma fraternidade racial brasileira. O imaginário diaspórico dos afro-americanos, que levava em consideração as experiências negras no continente africano e no Caribe, acabou incorporando o Brasil como referência de sociedade livre de práticas racistas.

Para um negro, visitar a América do Sul é certamente uma experiência valorosa e sem preço. As palavras não podem descrever o meu encanto ao observar a vida social do negro no Brasil, onde, sem precisar enfrentar obstáculos raciais, ele ascende socialmente e avança na escala de realizações, ainda que a emancipação dos escravos tenha acontecido somente em $1888 .{ }^{18}$

As narrativas do afro-americano, no entanto, não foram marcadas somente por elogios às ordens sociais inclusivas na América Latina. Os relatos de viagem de Robert Abbott foram organizados em dois eixos. No primeiro, o jornalista se preocupou em retratar para os leitores do Chicago Defender os exemplos de mobilidade social negra e de outras minorias nos países latino-americanos. No segundo eixo, o jornalista demonstrou uma influência negativa do racismo norte-americano sobre as nações latino-americanas. Abbott acreditava que a presença de cidadãos dos Estados Unidos - habituados a uma etiqueta racista em outros países poderia comprometer o padrão de relações raciais da América Latina. Na América do Sul, ele descreveu casos isolados de norte-americanos que tentaram evitar seu acesso a hotéis e restaurantes; entretanto, na região caribenha, relatou um processo acentuado de difusão do racismo norte-americano que construía uma hierarquia racial similar à dos Estados Unidos.

No Panamá, as dinâmicas sociais, segundo Robert Abbott, já haviam sido transformadas profundamente pelo imperialismo 
norte-americano. Na narrativa do jornalista, as fraternidades raciais sul-americanas deram espaço, então, a um processo de construção de hierarquias raciais de padrão norte-americano. Os panamenhos encaravam no cotidiano inúmeras práticas de discriminação que marginalizavam os trabalhadores negros. Abbott trouxe os comentários de um taxista que trabalhava na Zona do Canal do Panamá para ilustrar os perigos da influência do imperialismo norte-americano nas sociedades latino-americanas. Em 1903, os Estados Unidos haviam sido decisivos para a independência dos panamenhos da Colômbia, apoiando os rebeldes. A ação tinha o objetivo de garantir a autoridade dos norte-americanos sobre o Canal do Panamá, que tinha importância estratégica por ligar o oceano Atlântico ao Pacífico. Ao relatar a restrição dos negros a vários espaços da Zona do Canal e a desigualdade no tratamento de trabalhadores negros e brancos, Robert Abbott aproximou a realidade panamenha à norte-americana:

A força de trabalho empregada geralmente na construção do Canal é a de trabalhadores negros caribenhos. Os profissionais negros desfrutam de poucas oportunidades de emprego. Algum tempo atrás foi estabelecido o que se chama de fila de ouro e fila de prata, os empregados negros recebem os seus cheques através de uma janela especial que passou a se chamar de "fila de prata”. Os empregados brancos, que são a maioria nos negócios, constituem a "fila de ouro". Desde esses dias, essa prática vem se ampliando, tornando-se base da discriminação racial. Indo em direção à região costeira, eu pedi para um taxista negro me levar para um hotel de primeira classe. O homem fez uma expressão de perplexidade. "Porque, senhor?", ele disse, "se eu te levar para algum desses lugares que você me pediu, eu poderei perder a minha licença, negros não são atendidos em hotéis de primeira classe ou cafés da Zona do Canal". ${ }^{19}$

Robert Abbott, com seus relatos de viagem pelo Caribe, procurou demonstrar como a política externa do país, de formas variadas, 
contribuía para a difusão do padrão de racismo norte-americano que já oprimia a população afro-americana. Sua passagem por Cuba, apesar de seus elogios à arquitetura e à organização do espaço público de Havana, foi marcada também por um mal-estar nas relações entre negros e brancos. Assim como no caso do Panamá, os norte-americanos desfrutavam de uma autoridade constituída a partir do apoio militar do país à independência cubana em 1898. A Emenda Platt, que vigorou entre 1901 e 1933, garantia a intervenção dos ianques em Cuba para defender seus interesses. Para Abbott, a presença norte-americana poderia comprometer o legado espanhol em uma sociedade na qual se reconheciam apenas "distinções de classe e educação":

Quando Cuba se encontrava sob domínio espanhol não havia divisões raciais, todas as pessoas eram igualmente súditas do rei da Espanha, as divisões entre negros e brancos na sociedade cubana se manifestam somente a partir de possessões econômicas e educação. É verdade que não há mais riqueza e educação hoje do que em qualquer outro momento da história, e a ilha nunca foi tão saudável para viver. A influência americana tem feito muito para o povo cubano, mas, ao mesmo tempo em que há o espírito de progresso, outra coisa acompanha: o preconceito de raça americano, algo desconhecido para os cubanos antes da chegada dos americanos. ${ }^{20}$

Enquanto crítica contundente do racismo norte-americano, a retórica de Robert Abbott ia de encontro à pretensão dos Estados Unidos de se colocarem mundialmente como nação democrática, reforçando sempre o processo de marginalização dos negros no país e o esforço dos norte-americanos para hierarquizar racialmente as sociedades latino-americanas no Caribe e na América Central. Nesse sentido, a América do Sul, tendo como principal referência o Brasil, foi retratada como uma espécie de refúgio do racismo dos Estados Unidos, um espaço com fraternidades raciais que propiciaram a ascensão das populações negras no período pós-abolição. Em sua opinião, a nação norte-americana, apesar 
do progresso no campo econômico, apresentava um atraso na integração da população negra.

Assim que retornou aos Estados Unidos, Robert Abbott passou a se apresentar como especialista em assuntos sobre as populações negras na América Latina. Em conferências nas cidades de Chicago e Nova Iorque, o jornalista acusou seus compatriotas brancos, que viajaram e relataram suas experiências na América Latina, de esconderem a realidade dos negros pelo continente. Como um homem que havia tido a oportunidade de observar in loco as relações raciais pelas Américas, Abbott assumiu a função de testemunha ocular e reforçou o caráter harmonioso dos países da América do Sul. Nesse sentido, o Chicago Defender sistematicamente divulgou as fraternidades raciais entre seus leitores, popularizando o Brasil como espaço privilegiado de mobilidade social negra e de emergência de um novo negro. O periódico afro-americano gestou uma identidade transnacional.

\section{A Frente negra nas páginas do Chicago Defender}

Posteriormente à jornada de Robert Abbott pela América do Sul, o Chicago Defender reforçou a representação do Brasil como espaço de harmonia entre negros e brancos na América Latina. Com intuito de contrastar com o padrão de relações raciais nos Estados Unidos, reproduziu imagens de confraternização entre pessoas com diferentes tons de pele. A década de 1920, entre o ativismo afro-americano, foi marcada pela articulação em torno de uma lei antilinchamento. O linchamento de negros foi uma prática comum, principalmente nas comunidades do Sul, em que o objetivo era manter o controle sobre as populações negras. A percepção entre as lideranças era a de que somente com a criminalização de práticas violentas se poderia avançar no processo de desmantelamento do segregacionismo. Nesse sentido, a experiência brasileira, ainda que romantizada nas páginas do periódico negro, foi utilizada sistematicamente como referência positiva de convívio pacífico entre negros e brancos. Como as obras de David Hellwig e Amilcar Pereira demonstram, esse momento foi o auge da circulação da representação do Brasil como paraíso racial nos Estados Unidos. A partir do momento em 
que o Movimento pelos Direitos Civis ganhou terreno nas comunidades do Sul dos Estados Unidos, o interesse pelo Brasil foi desaparecendo. ${ }^{21}$

Assim, as representações sobre o Brasil respondiam a uma demanda do ativismo negro norte-americano, e o Chicago Defender tomou para si o papel de órgão difusor de informações sobre as sociedades latino-americanas. O periódico também publicou e reproduziu de outros jornais as opiniões de especialistas e turistas que corroboravam a existência de uma fraternidade racial brasileira. Entre 1923 e 1934, não há grandes mudanças na abordagem do periódico negro, que atribuía a singularidade dos brasileiros à influência portuguesa, como argumentaria Gilberto Freyre a partir de 1933.

A cobertura do Chicago Defender mudou na década de 1930, com a ascensão de uma classe de ativistas negros na cidade de São Paulo e a fundação da Frente Negra Brasileira (FNB) em 1931. Durante a viagem de Abbott ao Brasil, já havia entre os negros brasileiros um debate sobre a situação de marginalização da população negra. Enquanto o jornalista afro-americano testemunhava o que acreditava ser um modelo de fraternidade racial, articulava-se uma militância negra que se manifestaria por meio da publicação de jornais voltados para a comunidade negra de São Paulo. Essa mesma liderança questionou a afirmação de harmonia racial no Brasil, feita por Robert Abbott. Em artigo escrito no jornal Kosmos, em 1923, Abílio Rodrigues declarou que o jornalista afro-americano havia sido iludido e não compreendeu o modo como o preconceito de cor se manifestava no Brasil. A classe de negros ascendentes, celebrada por Abbott, havia, de fato, encarado muito preconceito na trajetória profissional. ${ }^{22}$

Em 1926, o Chicago Defender trocou exemplares com $O$ Clarim da Alvorada, principal publicação da imprensa negra de São Paulo na década de 1920. O jornal dos brasileiros publicou algumas notícias reproduzidas do jornal afro-americano, mas este não chegou a fazer menção à imprensa negra brasileira publicada por ativistas. A atuação do ativismo

21 David J. Hellwig (org.), African-American Reflections on Brazil's Racial Paradise, Philadelphia: Temple University Press, 1992; Amilcar Araujo Pereira, O mundo negro: relações raciais e a constituição do movimento negro contemporâneo no Brasil, Rio de Janeiro: Pallas, 2013. 
negro no Brasil comprometeria a representação positiva da sociedade brasileira nas páginas do Chicago Defender.

No entanto, a FNB - uma das principais organizações políticas do ativismo negro na primeira metade do século XX - atraiu bastante a atenção do Chicago Defender, tornando-se uma referência de ativismo negro na América Latina que poderia servir de exemplo para o ativismo dos afro-americanos. ${ }^{23}$ A década de 1930, com o impacto da crise de 1929 e a Grande Depressão, foi de apreensão para a população negra dos Estados Unidos. Se a taxa de desemprego era de $25 \%$ para os trabalhadores em geral, para os negros, especificamente, chegou a $45 \%$, acentuando as desigualdades sociais no país. ${ }^{24} \mathrm{O}$ Chicago Defender, por intermédio de Robert Abbott, criticou de maneira veemente o presidente Franklin Roosevelt, clamando por políticas específicas para a população negra. Em meio ao momento de crise, a FNB foi retratada como organização robusta de dimensão nacional com capacidade de arregimentar toda a massa negra, fenômeno que deveria ser acompanhado pelo periódico afro-americano.

A FNB foi resultado de um processo de institucionalização do ativismo negro da cidade de São Paulo ao longo da década de 1920. Em 1931, Francisco Costa dos Santos e Isaltino Veiga dos Santos iniciaram uma mobilização para criar uma organização que respondesse aos anseios da população negra em um momento de agitação na política brasileira, após a Revolução de $1930 .{ }^{25}$ Eles foram bem-sucedidos no recrutamento de associados: em um ano a FNB já tinha um quadro efetivo com cerca de seis mil membros. O discurso dos frentenegrinos reforçava a importância da integração do negro à sociedade brasileira, confrontando as ideias, ainda em circulação, de uma nação brasileira enbranquecida. ${ }^{26}$

23 Petrônio Domingues, "Como se fosse bumerangue: Frente Negra Brasileira no circuito transatlântico", Revista Brasileira de Ciências Sociais, v. 28 (2013), pp. 155-170.

24 Cheryl Lynn Greenberg, To Ask an Equal Chance: African-Americans in Great Depression, Plymouth: Rowman \& Littlefield Publishers, 2009, p. 56; Harvard Sitkoff, A New Deal for Blacks: The Emergence of Civil Rights as a National Issue: The Depression Decade, Oxford: Oxford University Press, 2009.

25 George Reid Andrews, Negros e brancos em São Paulo (1888-1988), Bauru: Edusc, 1998.

26 Sobre a Frente Negra Brasileira, cf. Petrônio Domingues, "A insurgência de ébano: a história da Frente Negra Brasileira (1931-1937)”, (Tese de Doutorado, Departamento de História da Universidade de São Paulo, 2005); e Regina Pahim Pinto, "Movimento negro em São Paulo: 
Entretanto a organização negra foi recontextualizada nas páginas do Chicago Defender. A Revolução de 1930 foi retratada como a ascensão do ditador Getúlio Vargas, aliado de racistas norte-americanos, que destruiria a fraternidade racial brasileira. O Brasil, nesse sentido, deixaria de simbolizar uma possibilidade de harmonia racial para se transformar em mais uma vítima do racismo internacional ianque, que já havia comprometido as relações sociais no Panamá e em Cuba. A FNB, portanto, na narrativa do jornal, foi articulada para lutar contra a estruturação de uma ordem social racista no Brasil.

A primeira referência à organização foi feita em 1933, dois anos após sua fundação. O Chicago Defender, em tom alarmante, retratou os esforços de ativistas negros do Brasil para organizar uma entidade capaz de fazer frente ao processo de hierarquização racial da sociedade brasileira, preservando a fraternidade racial, ameaçada pela difusão da supremacia racial norte-americana entre os brasileiros. O jornal reproduziu o relato de Robert Abbott sobre a América Latina, que lamentava a influência do racismo dos Estados Unidos sobre as relações raciais dos países latino-americanos, reforçando a profecia do jornalista que manifestara sua preocupação com a expansão do imperialismo dos Estados Unidos e seu caráter racista sobre a América do Sul. A suposta influência dos racistas norte-americanos não foi tratada como fenômeno difuso, mas como uma mobilização de sulistas interessados em recriar a $\mathrm{Ku}$ Klux Klan no Brasil. Os imigrantes norte-americanos, por meio de escolas e missões, separavam negros e brancos.

A atual situação do Brasil nos lembra da profecia de Robert S. Abbott, editor do Chicago Defender, que, quando esteve aqui há alguns anos, pediu aos brasileiros para que ficassem atentos às ofertas de amizade dos americanos e seu tipo especial de cristianismo. O senhor Abbott comentou que muito preconceito e discórdia são semeados pelos brancos do Sul que carregam suas atitudes perniciosas para o Norte e para o Leste dos Estados

luta e identidade", (Tese de Doutorado, Departamento de Antropologia da Universidade de São Paulo, 1993). 
Unidos. "Se vocês não os vigiarem de perto, eles farão a mesma coisa aqui", disse ele ante uma plateia de homens de negócios. ${ }^{27}$

A preocupação de Robert Abbott era com a falta de preparo dos brasileiros para enfrentar as práticas comuns ao repertório racista dos norte-americanos. AFNB, nesse sentido, ocuparia um vácuo de lideranças negras em um país sem tradição racista. No Chicago Defender, a organização negra logo ganharia destaque na seção de notícias internacionais, com reportagens e artigos que retratavam em detalhes lideranças, estrutura e estratégias para combater o racismo. Em artigo publicado em 1935, o jornal informou seus leitores sobre a organização de um congresso de frentenegrinos, citando figuras proeminentes como Vicente Ferreira, Guaraná Santana, Justiniano Costa e Arlindo Veiga dos Santos. A FNB foi descrita como uma mobilização de negros brasileiros que lutava pela preservação da democracia brasileira:

A organização se esforça para prevenir abusos da constituição e dos direitos civis, tentando estabelecer os verdadeiros princípios da democracia. Esse programa se fez necessário devido a algumas circunstâncias que restringiram a participação política dos negros brasileiros e às influências estrangeiras que limitaram suas esferas sociais e atividades cívicas. Esse não é somente um congresso da Frente Negra, mas um congresso de todos os negros brasileiros convocados para o propósito de consolidar os seus interesses e para promover objetivos que impulsionam a organização negra. ${ }^{28}$

A FNB, nesse sentido, foi transformada em uma organização política de excelência. Em editorial para o jornal Chicago Defender, Robert Abbott utilizou a experiência dos frentenegrinos no Brasil como exemplo de "energia intelectual negra" que poderia contribuir para o progresso de sociedades e indivíduos. Para o jornalista, os grandes movimentos da história eram resultados de ideias gestadas por mulheres e homens educados, capazes de conceber grandes projetos para a emancipação social e econômica. $\mathrm{O}$ ativismo brasileiro foi considerado uma referência de 
mobilização de negros que, por meio do esforço intelectual, confrontou uma ordem social que começou a criar barreiras raciais para sua população negra. A FNB foi retratada como organização "robusta", "a mais poderosa da América do Sul", com um excelente quadro de lideranças e recursos financeiros capaz de promover a inserção social de profissionais negros em diversas instituições. A iniciativa dos brasileiros deveria ser tomada como exemplo.

Com apenas alguns anos de idade, a Frente Negra é hoje a mais poderosa organização em toda a América do Sul. Ela tem dinheiro, tem cérebros e força numérica para lutar insistentemente contra qualquer tentativa de atacar os vários direitos dos negros, qualquer movimento que tenha como objetivo sua restrição, submissão ou isolamento. Esses homens têm lutado com os seus cérebros e irão lutar com suas mãos se necessário, eles não têm medo de morrer. ${ }^{29}$

A Revolução de 1930 no Brasil foi tratada como golpe com intuito de violar os direitos civis da população negra brasileira. Nesse sentido, o periódico afro-americano pintou um cenário tenebroso para seus leitores, onde os negros foram sistematicamente segregados de algumas instituições, experimentando as experiências pelas quais os negros nos Estados Unidos já haviam passado. Em artigo publicado em janeiro de 1936, lamentava-se que os brasileiros pudessem ter o mesmo destino dos norte-americanos. As forças racistas sob influência dos norte-americanos invadiam os grandes centros e comprometiam o regime de fraternidade racial. A FNB se organizava para enfrentar a ameaça estrangeira, unindo as lideranças negras e até mesmo atraindo o interesse de brasileiros brancos engajados na luta contra o preconceito racial.

A Frente Negra, como o nome indica, "Black Front", foi organizada com o objetivo de interromper a rápida violação dos direitos civis e constitucionais dos negros nativos que vêm sofrendo o mesmo destino dos negros americanos através da implantação 
no Brasil do preconceito e de seus males por brancos americanos que estabeleceram residência nos principais centros da república. ${ }^{30}$

A FNB foi uma das organizações negras mais importantes de São Paulo e do Brasil no período, porém nunca chegou a alcançar o tamanho atribuído a ela nas páginas do Chicago Defender. Sua estrutura serviu de referência para outras organizações negras e estimulou a criação de filiais em outras regiões do território brasileiro, mobilizando ativistas em cidades como Santos, Sorocaba, Campinas, Rio de Janeiro, Salvador, Pelotas e Recife, gerando especulações sobre números que estimavam entre quinze mil e cem mil associados.

Os ativistas frentenegrinos se engajaram em várias lutas que tinham como objetivo a inclusão de trabalhadores negros em diversas instituições públicas, destacando-se o caso da Guarda Civil que, embora oficialmente não discriminasse negros, tinha um quadro majoritário de brancos. Os clamores da FNB para que cidadãos negros fossem admitidos chegaram até o presidente Getúlio Vargas, que ordenou a contratação de cerca de duzentos recrutas negros. Nesse sentido, a organização negra conseguiu estabelecer canais de expressão na grande imprensa, transformando-se em um grupo de pressão. ${ }^{31}$ No entanto ela nunca teve poder para influenciar os partidos políticos e pautar suas agendas. Quando se tornou um partido político, depois de vários indeferimentos por parte dos tribunais eleitorais, em 1936, a FNB não teve a oportunidade de testar sua base eleitoral, já que o golpe getulista instaurando o Estado Novo, em 1937, colocou na ilegalidade todos os partidos brasileiros.

As distorções da realidade brasileira divulgadas pelo Chicago Defender parecem ter tido a contribuição do afro-americano Alfred Clendenen, correspondente do jornal no Brasil e anfitrião de Robert Abbott durante sua visita ao Rio de Janeiro. Clendenen entendia que naquele momento se estruturava uma ordem social dividida racialmente entre os brancos e as demais "raças", o que provocaria conflitos raciais em diversas sociedades. Nesse sentido, as nações europeias e os Estados Unidos

30 "Whites in Brazil Ask Members of Frente Negra for Admittance", Chicago Defender, 25/01/1936, p. 24.

31 Sobre a Frente Negra Brasileira, cf. Domingues, A insurgência de ébano; e Pinto, Movimento negro em São Paulo. 
representavam forças brancas racistas que não estavam necessariamente articuladas, mas procuravam submeter os povos africanos e asiáticos. As consequências desse conflito, portanto, se manifestariam no Brasil a partir da supressão da democracia e da marginalização dos negros brasileiros. Contudo, neste momento, todos os movimentos políticos negros pelo mundo, incluída a FNB, demonstravam força para fazer frente aos brancos racistas que se encontravam em "decadência". Na sua perspectiva, seria necessária a unidade das populações negras de todo o mundo:

De acordo com o meu raciocínio, nós temos que concentrar esforços em uma unidade, porque os nossos membros estão sendo marginalizados em quase todos os países, e somente através do medo de uma super-raça deve se organizar para o futuro.

Não há nenhuma razão substancial para se ter algum medo da raça branca, a única delas que não está em declínio é a americana, porque ela é o resultado da mistura de diferentes raças brancas. O inglês, por exemplo, está decaindo anualmente: alguns dias atrás eles permitiram aos fracos alemães um limite parcial para o programa naval, demonstrando fraqueza política. Não precisamos ter medo deles no futuro. ${ }^{32}$

Invertendo a lógica racista do período, Clendenen considerou os brancos como uma raça débil e clamava pela articulação dos negros. A trama maluca do correspondente do Chicago Defender e outras reportagens superestimaram o poder da FNB. As lideranças da organização jamais fizeram qualquer tipo de menção a uma ameaça de norte-americanos à sociedade brasileira. A preocupação de alguns deles era com o fluxo de imigração de trabalhadores europeus, que eram acusados de tomar o lugar dos trabalhadores nacionais no mercado de trabalho que se formava na cidade de São Paulo. O processo de marginalização dos negros com a política de imigração foi enfrentado com discursos xenófobos e demandas pelo controle ou fim do fluxo de trabalhadores estrangeiros no Brasil. Assim, os frentenegrinos não fizeram oposição 
ao governo de Getúlio Vargas, ao contrário, o aclamaram pelo caráter nacionalista de suas políticas, associadas à valorização do trabalhador nacional e, consequentemente, dos trabalhadores negros.

$\mathrm{O}$ fato é que a emergência da FNB nas páginas do Chicago Defender comprometeu o discurso do próprio periódico sobre a fraternidade racial no Brasil. As notícias do enfrentamento entre a organização política negra e o regime ditatorial, com seus aliados norte-americanos, interessado em instaurar uma hierarquia racial, prevaleceu sobre a tradicional cobertura que destacava a ascensão de profissionais negros na sociedade brasileira. O Brasil, assim como havia acontecido com Panamá e Cuba, na narrativa criada pelo periódico negro, foi engolido pelo racismo difundido pelos norte-americanos pelas Américas.

As notícias sobre o Brasil diminuíram no final da década de 1930 e de maneira acentuada após a morte de Robert Abbott, o entusiasta em relação à sociedade brasileira, em 1940. Já a FNB, que havia se animado com o nacionalismo de Getúlio Vargas, mesmo após perder o direito de se organizar politicamente no Estado Novo, definhou porque não foi capaz de se reinventar em outro contexto político. O golpe de Vargas acabou decretando o fim da organização negra, que ensaiou seu retorno inúmeras vezes.

Nas páginas do Chicago Defender, conforme apontam Domingues e Pereira, a FNB foi celebrada como referência de ativismo que deveria ser seguida pelos afro-americanos. ${ }^{33}$ A metáfora do bumerangue, utilizada de maneira perspicaz por Domingues, revela as dinâmicas de um amplo espaço transnacional, no qual atores da diáspora negra circulam e difundem informações. Nesse quadro amplo, negros brasileiros e norte-americanos, em diferentes momentos, foram procurar referências positivas de ativismo fora de seus contextos nacionais. Entre as décadas de 1920 e 1930, a imprensa negra brasileira apontou para seus leitores os desafios e conquistas dos afro-americanos, assim como lideranças negras dos Estados Unidos - como Robert Abbott - identificaram nas experiências negras brasileiras soluções e alternativas para o ativismo norte-americano. 
Entretanto o conjunto de narrativas sobre o Brasil e a América Latina, organizado por Robert Abbott, não se restringiu à admiração pelo padrão latino de relações raciais e a organização da FNB. Outro eixo de narrativas sobre a América Latina era o da influência do racismo norte-americano sobre o resto das Américas. Essa perspectiva, de certa forma, se aproximava da noção de color line utilizada sistematicamente pelo intelectual negro William Du Bois para retratar o processo de racialização no Ocidente proporcionado pela escravidão e pelo colonialismo. Robert Abbott entendia que a projeção dos Estados Unidos sobre a América Latina impulsionava, para além do Sul do país, uma fronteira de racialização que minava o "padrão pacífico" de relações raciais latino-americanas. ${ }^{34} \mathrm{Ou}$ seja, para Abbott, o imperialismo norte-americano era essencialmente racista.

Nesse sentido, as ações da FNB não foram retratadas somente como um exemplo positivo de organização política, mas como uma reação à aproximação da "fronteira racial norte-americana" ao Brasil. A criação da FNB, em uma sociedade supostamente livre do racismo, na visão de Robert Abbott, seria o primeiro passo para enfrentar um fenômeno que já havia destruído a fraternidade racial cubana e de outros países da América Central e do Caribe.

\section{Conclusão}

Robert Abbott, por meio do Chicago Defender, procurou difundir entre os afro-americanos a existência de fraternidades raciais na América Latina. O objetivo do jornalista era demonstrar ao seu público que era possível estabelecer uma ordem social alternativa à hierarquia racial constituída na sociedade norte-americana. Nesse sentido, as representações sobre a harmonia racial latino-americana, que ignoraram as singularidades do racismo praticado entre latino-americanos, foram exploradas e mobilizadas pelo periódico negro em um contexto de luta pela igualdade de direitos na sociedade norte-americana. A agenda política de Robert Abbott

34 Para ver uma discussão sobre o conceito de color line em contexto internacional, cf. Marilyn Lake e Henry Reynolds, Drawing the Colour Line: White's Men Country and The International Challenge to Racial Equality, Cambridge: Cambridge University Press, 2008. 
pregava o integracionismo, e nações como o Brasil foram utilizadas como exemplos de sociedades que supostamente haviam promovido a mobilidade social de suas populações negras no pós-abolição.

Por outro lado, o editor do Chicago Defender manifestou sua preocupação com o que entendeu ser uma ameaça do racismo norte-americano difundido pela presença de agentes do imperialismo dos Estados Unidos nos países da América Latina. Quando a FNB emergiu em uma sociedade considerada um paraíso racial aos olhos dos afro-americanos, a interpretação foi a de que a influência norte-americana que havia afetado o Panamá e Cuba chegara à América do Sul. O Chicago Defender elogiou o ativismo dos negros brasileiros, demonstrando que a FNB poderia servir como modelo de organização política; entretanto, as representações sobre as fraternidades raciais na América Latina foram comprometidas por uma narrativa confusa e imprecisa sobre o confronto entre uma articulação nacional de negros e um ditador aliado a racistas norte-americanos.

Recebido em 25/05/2018 e aprovado em 08/09/2019 


\section{Resumo}

O objetivo deste artigo é demonstrar, a partir da publicação de notícias sobre a Frente Negra Brasileira (1931-1937), a construção de representações sobre as relações raciais no Brasil e na América Latina no jornal afro-americano Chicago Defender entre 1916 e 1940. Por um lado, o periódico negro divulgou entre seus leitores a ideia de fraternidades raciais estabelecidas nas nações latino-americanas, principalmente no Brasil. Por outro, demonstrou como a influência de um imperialismo norte-americano que poderia comprometer as relações sociais na América Latina pela difusão internacional de práticas racistas que haviam marginalizado os negros nos Estados Unidos já afetava a América Central. A ascensão da Frente Negra Brasileira foi considerada pelos jornalistas do Chicago Defender como o sinal do "perigo da influência racista norte-americana" nos países da América do Sul.

Palavras-chave: Frente Negra Brasileira - imprensa afro-americana - racismo - fraternidade racial.

\section{Abstract}

This article uses news on Brazilian Black Front (1931-1937) to demonstrate the construction of representations of Brazilian and Latin American racial relations in the African-American newspaper Chicago Defender between 1916 and 1940. On the one hand, the Black periodical spread among its readers the idea that racial fraternities existed in Latin American nations, especially Brazil. On the other hand, the newspaper showed how the influence of an American imperialism which could jeopardize Latin American social relations by diffusing racist practices that had marginalized Blacks in the United States was already having a negative impact on Central America. The rising of the Brazilian Black Front was regarded by Chicago Defender journalists as a sign of "the danger posed by racist American influence" on South American countries.

Keywords: Brazilian Black Front - African-American press - racism-racial fraternity. 